\title{
Economics at the Federal Communications Commission ${ }^{\text {th }}$
}

\author{
LESLIE M. MARX ${ }^{1,2}$ \\ ${ }^{1}$ Federal Communications Commission, Washington, D.C., U.S.A. \\ ${ }^{2}$ Fuqua School of Business, Duke University, Box 90120, Durham, NC 27708-0120. \\ E-mail:marx@duke.edu
}

\begin{abstract}
This article reviews several issues confronted by the Federal Communications Commission (FCC) over the past year and discusses some of the economic analysis employed by the FCC in examining these issues. The article also identifies areas in which future academic research would be valuable to the agency.
\end{abstract}

Key words: a la carte, multichannel video programming, net neutrality, spectrum auctions.

\section{Introduction}

The Federal Communications Commission (FCC) is responsible for ensuring that U.S. telecommunications markets perform in a manner consistent with various statutory objectives. These markets include radio; broadcast, satellite, and cable television; and wireline and wireless (mobile) telephony. This article discusses several important policy issues that FCC economists confronted over the past year and describes some of the analysis used in examining those issues. The article also identifies areas of future academic research that have particular relevance for the agency.

Section 2 discusses some auction design issues that have arisen during the last year with respect to the FCC's spectrum license auctions. Section 3 discusses issues in the cable television industry that have received attention over the past year. Section 4 discusses the actively debated topic of net neutrality. Section 5 contains brief conclusions.

\footnotetext{
s Thanks are due to Heather Dixon, David Fiske, Evan Kwerel, Jonathan Levy, and Larry White (the editor) for useful comments. The opinions expressed here are those of the author and do not necessarily reflect those of the FCC, its staff, or commissioners.
} 


\section{Auction Design}

The FCC has held auctions for spectrum licenses since $1994 .{ }^{1}$ The initial auction design was extremely innovative when first introduced. The FCC, working with academic economists and the wireless industry, invented something new because the usual auction designs do not work well for selling a large number of different objects that have strong complementaries as well as substitution possibilities. In particular, in that environment, bidders need to be able to shift their bidding among substitutes and to bid simultaneously on licenses that they would like to acquire together. Bidders may need to know the full package of licenses that they are likely to win in order to know how much they are willing to bid for the individual licenses. For example, if their business plan calls for regional coverage, they may not want any licenses at all unless they can get licenses that provide good coverage of an entire region.

The FCC had to find a way to sell multiple different objects at the same time while still retaining the flavor of the usual 'open outcry' auction so that bidders could aggregate the collections of licenses that they needed for their business plans and pursue backup strategies as license prices changed during the auction. In the end, and based on substantial input from FCC economists and academic economists, the FCC developed a simultaneous multiple round (SMR) auction, also known as a simultaneous ascending auction. This auction design has been the mainstay of FCC auctions since 1994.

In the past year, there have been two interesting innovations to the FCC's auction design. First, in Auction 65, the FCC decided to use an auction to select among multiple competing band plans; and second, in Auction 66, the FCC modified the SMR auction design to keep bidder identities anonymous if the auction is not expected to be sufficiently competitive. These two auctions are the subject of the remainder of this section.

\section{AUCTIONS WITH MULTIPLE CONFLICTING BAND PLANS}

In May 2006, the FCC began Auction 65 for Air-to-Ground Radiotelephone Service. In that auction, bidders are able to express their preferences among three mutually incompatible 'band plans.' A 'band plan' is a specification of what frequency bands will be assigned to the different licenses being offered at the auction.

Announcing Auction 65 in a January 2006 Public Notice, the FCC stated that for Auction 65, instead of offering a single band plan, as has

${ }^{1}$ See McMillan (1994), McAfee and McMillan (1996), Cramton (1997), and Kwerel and Rosston (2000). 
Air-Ground Service

$800 \mathrm{MHz}$ Commercial Service Band Plan

Ground

Airborne

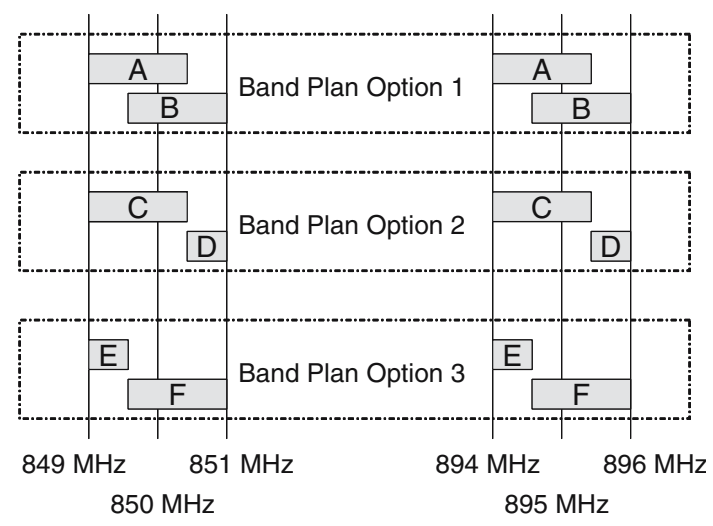

Figure I. Band Plan for Auction 65.

been done in the past, the FCC would offer three different, mutually exclusive band plans and allow the auction itself to determine which band plan would ultimately prevail. As stated in the public notice, Auction 65 offers two new nationwide commercial Air-Ground Radiotelephone Service licenses in the $800 \mathrm{MHz}$ band in three alternative band configurations: (1) Band Plan 1, composed of two overlapping, shared, $3 \mathrm{MHz}$ licenses (Licenses A and B, respectively); (2) Band Plan 2, composed of an exclusive $3 \mathrm{MHz}$ license and an exclusive $1 \mathrm{MHz}$ license (Licenses $\mathrm{C}$ and $\mathrm{D}$, respectively); and (3) Band Plan 3, composed of an exclusive $1 \mathrm{MHz}$ license and an exclusive $3 \mathrm{MHz}$ license (Licenses $\mathrm{E}$ and $\mathrm{F}$, respectively), with the blocks at opposite ends of the band from Band Plan 2. Licenses in only one of these mutually incompatible band configurations will be awarded. See Figure I. ${ }^{2}$

In order to promote competition in the $800 \mathrm{MHz}$ air-ground band, the Commission has prohibited any party from obtaining a controlling interest, either at auction or by a post-auction transaction, in new licenses for more than three megahertz of spectrum (either shared or exclusive) in the band. No single party, therefore, may win in the auction more than one license in any of the available band configurations. The auction will be used to determine which band plan provides the greatest value and then award the licenses based on the bids submitted for that band plan. Specifically, bidders will have the opportunity to bid on the licenses in each of the three band plans, and then ultimately the band plan with the highest total bids will be the one adopted.

\footnotetext{
${ }^{2}$ Available at http://wireless.fcc.gov/auctions.
} 
This auction format allows market forces to determine what band plan is ultimately adopted rather than relying on the more political process that usually determines the single band plan to be offered at an FCC auction. ${ }^{3}$

\section{ANONYMOUS AUCTIONS}

Although the FCC's auction program has been highly successful, the susceptibility of FCC auctions to collusion has received attention in the economics literature. ${ }^{4}$ Economic theory, empirical evidence, and experimental evidence suggest that bidders may be able to collude to divide up the licenses, reducing auction revenue and, possibly, the efficiency of license assignment. Even without explicit collusion among bidders, strategic bidding can distort prices, result in inefficient assignments of licenses, and reduce competition and so lead to higher prices for final consumers.

The FCC has continued to refine its auction design to make it more robust against collusion and strategic bidding. One collusive device used in past auctions, signalling through the use of trailing digits in bids, has been eliminated by requiring bidders to bid by clicking radio buttons for a limited number of possible bid amounts in each round. In addition, the FCC no longer reports the time stamps associated with bids to prevent their use as signals; ${ }^{5}$ the FCC no longer allows the use of activity requirement waivers by bidders who have actively bid in a round to prevent their strategic use; and the FCC limits the use of withdrawals to prevent their abuse.

But other design features of the FCC auctions have continued potentially to facilitate strategic behavior by bidders, and this strategic bidding has continued to be a concern to the FCC. Specifically, one feature of most previous FCC auctions is that, after each round of bidding, the FCC announced publicly what every bidder did during that round. These announcements included winning bids, losing bids, who won each license, and who used waivers. The potential use of this information for strategic and/or collusive purposes has been a concern

3 As described in the Air-Ground Order at 25-29 (20 FCC Rcd at 4405, released 2/22/2005, available at http://hraunfoss.fcc.gov/edocs_public/attachmatch/FCC-04-287A1.doc) four parties-AirCell, Boeing, Space Data, and Verizon Airfone - submitted detailed proposals regarding revision of the band plan; however, each offered a different proposal for reconfiguration of the band. The FCC "reviewed the extensive record in this proceeding and carefully weighed the parties' competing proposals to reconfigure the $800 \mathrm{MHz}$ air-ground spectrum band" and concluded that the public interest was served by adopting a flexible framework (Air-Ground Order at 29 ). In other cases, a review of the record and weighing of competing proposals has led the FCC to select a single band plan.

4 See, e.g., Brusco and Lopomo (2002), Cramton and Schwartz (2000, 2002), Kwasnica and Sherstyuk (2001), and McAfee and McMillan (1996).

5 When time stamps are revealed, a bidder could potentially signal by submitting bids in two batches, one early in the round and one late in the round, with the two batches intended as a suggestion of a division of licenses between it and a rival bidder. 
of the FCC. Strategic bidding includes bidding strategies such as retaliatory bidding, attempts by bidders to establish reputations for retaliatory bidding to deter others from bidding against them, attempts to signal divisions of the market or trades of licenses in different geographic areas, gaming of the auction's activity rule through 'parking, ${ }^{6}$ and other attempts to deter or foreclose entry into markets.

Strategic bidding is harmful for a number of reasons. Strategic bidding distorts prices in the auction, ${ }^{7}$ and hence reduces efficiency; it can result in an inefficient assignment of licenses; and it can reduce competition in the final market and consequently lead to higher prices for consumers.

The FCC recently sought comments on its proposal to withhold certain bidding information during Auction 66 for Advanced Wireless Services (AWS-1), scheduled to begin August 9, 2006. Specific examples described in the Department of Justice's (DoJ) comments on the AWS-1 Public Notice show how strategic bidding can put small bidders, in particular, at a disadvantage. In their conclusion, the DoJ states that,

"Although the FCC has adopted other mechanisms to reduce opportunities for collusion, under the current auction procedures knowledge of bidder identities associated with particular bids still can facilitate coordinated behavior by sophisticated and better financed auction participants and potentially result in less opportunity for smaller bidders to compete for certain licenses." 8

For these reasons, the FCC has always had concerns about releasing information about the identities of the provisionally winning bidders.

${ }^{6}$ FCC auctions require the bidders to continue to bid actively in order to retain their eligibility to bid in future rounds. Specifically, the amount of the upfront payment submitted by a bidder determines the initial maximum eligibility (in bidding units) for each bidder. In order to ensure that the auction closes within a reasonable period of time, an activity rule requires bidders to bid actively throughout the auction, rather than wait until the end before participating. Bidders are required to be active on a specific percentage of their maximum eligibility during each round of the auction to avoid having their eligibility reduced. The minimum required activity level is expressed as a percentage of the bidder's maximum bidding eligibility, and increases by stage as the auction progresses. (For more details, see, e.g., the Public Notice released October 5, 2000, for the "C and F Block Broadband PCS Spectrum Auction," Report No. AUC-00-35-E, at 24-25, available at http://wireless.fcc.gov/auctions/35/releases/da002259.pdf.) One way to maintain eligibility without driving up the price of licenses on which a bidder is interested is to bid on other licenses that the bidder does not want, but where the bidder is fairly confident that it will be outbid in future rounds. This practice is referred to as 'parking.'

${ }^{7}$ Bidders rely on prices as they evolve during the course of the auction for information about ultimate market values. These prices are more likely to reflect true market values and thus provide better information if they are not distorted through strategic bidding behavior.

8 Department of Justice Comments at 10, DA 06-238, AU Docket No. 06-30, available at http://gullfoss2.fcc.gov/prod/ecfs/retrieve.cgi?native_or_pdf=pdf\&id_document=6518331764. 
In considering whether to withhold bidder identities, the FCC must balance the potential for such information to enhance efficiency against the danger that it might facilitate harmful strategic behavior. There are situations in which more information would be socially useful. For example, if some of the licenses are 'shared' as in Auction 65 for the Air-to-Ground Services, then it might be useful to know with whom you will be sharing the license. Bidder identities might provide some efficiency enhancing information about likely standards, which affects the ability to roam in adjacent geographic areas and the cost of mobile units because of economies of scale. However, technological change has reduced the cost of providing interoperability through multimode mobile radios; and bidders typically already know the standards in use on much of the spectrum and the identities of possible partners for roaming agreements.

Even in cases where knowing which firm will ultimately control certain licenses might have socially beneficial value, the information provided in the course of an auction falls short of that. As the DoJ commented:

"First, knowing who the current leading bidder is for a block is not the same as knowing the winner of a block, as a new high bid might be placed by another firm that uses a different technology. Second, given the dynamic nature of the wireless industry and ongoing advances in technology, the technology that actually will be deployed in this AWS spectrum is not known with certainty now, and may still be uncertain at the time of the auction's close and for some time thereafter... All winning bidders will be in a better position to determine what technology they will use or roaming partners they will seek after the auction rather than before, and information available from bidder identities during the auction will likely be of little relevance to the bidding decisions and business plans of firms participating in the auction."

There may also be concerns about the FCC's ability to keep information confidential until after the end of the auction; but since the FCC has replaced on-site bidding with remote bidding, it should be possible to conceal the identities of bidders during the auction. The sharing of information between bidders would be a violation of the FCC's formal anti-collusion rules. To preserve transparency, after the auction is over, all information would be released to the public.

The economics literature on the deterrence of anticompetitive behavior at auctions indicates that the seller should not provide bidders with information that they do not need since that additional information then

9 Department of Justice Comments at 9-10, DA 06-238, AU Docket No. 06-30, available at http://gullfoss2.fcc.gov/prod/ecfs/retrieve.cgi?native_or_pdf=pdf\&id_document=6518331764. 
open avenues for communication, signaling, and collusion. ${ }^{10}$ The FCC's proposed approach of restricting information about other bidders, but releasing all information about license characteristics and prices, is an application of the well-established market principle that the public will not be well served by allowing buyers or sellers to collude.

Nevertheless, the intuition that access to certain types of information promotes efficiency is correct. In particular, information about the characteristics of the objects being sold has been shown to promote efficiency. For example, McAfee and McMillan (1987) state (p. 730), "More accurate information about the item's true value mitigates the effects of the winner's curse in causing the bidders to be cautious..." and (p. 734) "You can encourage the bidders to raise their bids by having a policy of publicizing any information you yourself have about the item's true value." 11 With this in mind, the FCC has tried to make all available information on the definitions and characteristics of the licenses being sold available to the public.

However, unlike information about the objects being sold, information regarding the bids of rivals, contrary to promoting efficiency, can instead promote collusion, especially in an auction setting. For example, Marshall and Marx (2006) show that information on the identity of the winner of an auction facilitates collusion at a single-object auction. Brusco and Lopomo (2002) show that this effect is even more important in simultaneous ascending bid auctions such as those run by the FCC. The importance of the issue of collusion in auction design is highlighted in a survey article by Klemperer (2002), who states (p. 170), "A first major set of concerns for practical auction design involves the risk that participants may explicitly or tacitly collude to avoid bidding up prices." 12

10 This idea goes back to Adam Smith, who states in Chapter 10 of the Wealth of Nations: "People of the same trade seldom meet together, even for merriment and diversion, but the conversation ends in a conspiracy against the public, or in some contrivance to raise prices. It is impossible, indeed, to prevent such meetings, by any law which either could be executed, or would be consistent with liberty and justice. But though the law cannot hinder people of the same trade from sometimes assembling together, it ought to do nothing to facilitate such assemblies, much less to render them necessary."

11 For similar points, see also Milgrom (2004).

12 Klemperer (2002) goes on to recount an example from the spectrum auctions in Germany, stating, "in 1999, Germany sold ten blocks of spectrum by a simultaneous ascending auction [same format as the FCC] with the rule that any new bid on a block had to exceed the previous high bid by at least 10 percent. Mannesman's first bids were 18.18 million deutschmarks per megahertz on blocks $1-5$ and 20 million DM per $\mathrm{MHz}$ on blocks 6-10; the only other credible bidder-T-Mobil[sic]-bid even less in the first round. One of T-Mobil's managers then said (Stuewe (1999), p. 13): 'There were no agreements with Mannesman. But [T-Mobil] interpreted Mannesman's first bid as an offer.' The point is that 18.18 plus a 10 percent raise equals approximately 20 . It seems T-Mobil understood that if it bid 20 million DM per $\mathrm{MHz}$ on blocks 1-5, but did not bid again 
It is the view of the FCC's Wireless Telecommunications Bureau that because of the industry's development and the increased information available today regarding license valuations, and because of the particular characteristics of the AWS-1 auction, for that auction the possible legitimate values of bidder information are diminished and the potential for abuse is magnified. ${ }^{13}$ In the AWS-1 auction, there are over 1100 licenses and multiple spectrum blocks being offered in each geographic area, and the number of bidders is expected to be relatively low compared to the number of licenses offered, so the potential for anti-competitive bidding behavior is greater. Thus, the Bureau's judgment is that for this auction, it is appropriate for the FCC to withhold information about bidder identities until the auction is over.

Ultimately, the FCC established procedures for the AWS-1 auction that depend on the competitiveness of the auction, with the idea that strategic bidding and collusion are less of a concern when the auction is highly competitive. ${ }^{14}$ In those cases the FCC will provide full information, so any benefits that stem from bidders' having information about other bidders' identities can be realized. However, if the auction is not expected to be competitive, then concerns about strategic bidding and collusion are greater, and the FCC will withhold certain information on bidder identities. The basis for the decision on whether the auction is expected to be sufficiently competitive or not is to be based on an estimate of aggregate excess

Footnote 12 Continued

on blocks 6-10, the two companies would then live and let live with neither company challenging the other on the other's half. Exactly that happened. So the auction closed after just two rounds with each of the bidders acquiring half the blocks for the same low price (Grimm et al, 2001; Jehiel and Moldovanu, 2001)."

Giving another example, on p.171 Klemperer (2002) states, "In a multilicense U.S. spectrum auction [held by the FCC] in 1996-1997, U.S. West was competing vigorously with McLeod for lot number 378: a license in Rochester, Minnesota. Although most bids in the auction had been in exact thousands of dollars, U.S. West bid $\$ 313,378$ and $\$ 62,378$ for two licenses in Iowa in which it had earlier shown no interest, overbidding McLeod, who had seemed to be the uncontested high bidder for these licenses. McLeod got the point that it was being punished for competing in Rochester and dropped out of that market. Since McLeod made subsequent higher bids on the Iowa licenses, the "punishment' bids cost U.S. West nothing (Cramton and Schwartz, 1999)."

13 See "Auction of Advanced Wireless Services Licenses Scheduled for June 29, 2006; Comment Sought on Reserve Prices or Minimum Opening Bids and Other Procedures," Public Notice, 21 FCC Rcd 794 (2006) at 6-7, available at http://hraunfoss.fcc.gov/ edocs_public/attachmatch/DA-06-238A1.pdf.

14 For complete details, see FCC, "Auction of Advanced Wireless Services Licenses Scheduled for June 29, 2006; Notice and Filing Requirements, Minimum Opening Bids, Upfront Payments and Other Procedures for Auction No. 66," AU Docket No. 06-30, FCC 06-47, available at http://hraunfoss.fcc.gov/edocs_public/attachmatch/FCC-0647A1.pdf. 
demand at the beginning of the auction. Excess demand is measured by the ratio of total bidding eligibility to total available spectrum. A bidder's upfront payment determines its eligibility to bid at the auction. The total upfront payments of all bidders are to be compared to the total upfront payment that would be required in order for a bidder to be eligible to bid on all licenses available at the auction (with the modification that, for the purposes of the calculation, each bidder's upfront payment is capped at half of the upfront payment required to be eligible to bid on all licenses). If the ratio of the (modified) total upfront payments of the bidders to the upfront payment required to be eligible to bid on all licenses is more than three, ${ }^{15}$ then the auction will be viewed as sufficiently competitive that limiting information on the identities of bidders is not necessary.

If the threshold is not met, the FCC will withhold the following information until after the close of the auction: (1) bidders' license selections on their short form applications (Form 175); and (2) the identities of bidders that placed bids in each round, as well as other information on bidder activity and eligibility. But the FCC will disclose the identities of the bidders and their upfront payments. During the auction, FCC will disclose at the end of each round of bidding the amount of every bid placed in each round, but not the identity of the bidder that placed any particular bid in that round. ${ }^{16}$

It is the view of the FCC that the procedures adopted for the AWS-1 Auction will further enhance the likelihood that the AWS-1 auction will assign licenses in an efficient and competitive way.

\section{Multichannel Video Programming Distribution Industry}

In this section, I begin by reviewing the data on prices in the multichannel video programming distribution (MVPD) industry. I then discuss the issue of bundling and a la carte pricing of cable channels and the issue of video franchise reform.

\section{MARKET PERFORMANCE IN THE MVPD INDUSTRY}

For more than a decade, consumers and policymakers alike have expressed recurring concern and frustration about certain aspects of the performance of the cable television industry, the dominant supplier in multichannel video programming distribution (MVPD) markets across the United States.

${ }^{15}$ For a discussion of the threshold, see the ex parte submission of T-Mobile USA, Inc., filed in FCC Proceeding 06-30 on 03/20/06.

${ }_{16}$ Technically, it is the 'gross' amount of each bid that will be revealed, rather than the 'net' amount after accounting for any small bidder preferences. 
Table I. Cable Prices 1995-200519

\begin{tabular}{|c|c|c|c|c|c|}
\hline \multirow[t]{2}{*}{ Date } & \multicolumn{4}{|c|}{ Basic and Expanded Basic Programming Service } & \multirow[t]{2}{*}{$\mathrm{CPI}$} \\
\hline & $\begin{array}{l}\text { Price } \\
\text { of } \\
\text { Basic } \\
\text { Tier }\end{array}$ & $\begin{array}{l}\text { Price } \\
\text { of } \\
\text { Expand } \\
\text { Basic } \\
\text { Tier }\end{array}$ & Total Price & Channels & \\
\hline July 1995 & - & - & $\$ 22.35$ & 44.0 & 150 \\
\hline July 1996 & - & - & $\$ 24.28$ & 47.0 & 154 \\
\hline July 1997 & - & - & $\$ 26.31$ & 49.4 & 159 \\
\hline July 1998 & $\$ 12.06$ & $\$ 15.82$ & $\$ 27.88$ & 50.1 & 162 \\
\hline July 1999 & $\$ 12.58$ & $\$ 16.36$ & $\$ 28.94$ & 51.1 & 164 \\
\hline July 2000 & $\$ 12.84$ & $\$ 18.38$ & $\$ 31.22$ & 54.8 & 169 \\
\hline July 2001 & $\$ 12.84$ & $\$ 20.91$ & $\$ 33.75$ & 59.4 & 175 \\
\hline January 2002 & $\$ 13.06$ & $\$ 23.15$ & $\$ 36.21$ & 62.7 & 177 \\
\hline January 2003 & $\$ 13.45$ & $\$ 25.50$ & $\$ 38.95$ & 67.5 & 182 \\
\hline January 2004 & $\$ 13.80$ & $\$ 27.24$ & $\$ 41.04$ & 70.3 & 185 \\
\hline January 2005 & $\$ 14.30$ & $\$ 28.74$ & $\$ 43.04$ & 70.5 & 191 \\
\hline 1-year change, 2004-2005 & $3.6 \%$ & $5.5 \%$ & $4.9 \%$ & $0.3 \%$ & $3.0 \%$ \\
\hline 5-year change, 2000-2005 & $11.4 \%$ & $56.4 \%$ & $37.9 \%$ & $28.6 \%$ & $13.0 \%$ \\
\hline 10-year change, 1995-2005 & - & - & $92.6 \%$ & $60.2 \%$ & $26.9 \%$ \\
\hline
\end{tabular}

As shown in Table I, cable prices have almost doubled since 1995. In contrast, over that same period of time, the CPI increased by only $27 \% .{ }^{17}$

The data in Table I are drawn from a series of FCC surveys of cable prices, conducted pursuant to statutory instructions. Specifically, the Cable Act requires the Commission to compare the average rates of cable operators subject to 'effective competition,' as identified through specific adjudications, with those of cable operators that have not been found subject to 'effective competition.' ${ }^{18}$ The figures for 1999-2005 are

17 Source: BLS, All Urban Consumers, U.S. City Average (monthly series, extracted April 20, 2006), Series ID CUUR0000SA0, All Items Less Food and Energy.

1847 U.S.C. $\$ 543(\mathrm{k})(1)$ (cross-referencing 47 U.S.C. §543(a)(2)).

${ }^{19}$ Sources: FCC Cable Price Survey (2006) and previous Survey Reports including Statistical Report on Average Rates for Basic Service, Cable Programming Service, and Equipment, 20 FCC Rcd 2718 (2005); 18 FCC Rcd 13284 (2003); 17 FCC Rcd 6301 (2002); 16 FCC Rcd 4346 (2001); 15 FCC Rcd 10927 (2000); 14 FCC Rcd 8331 (1999); and 12 FCC Rcd 3239 (1997). Missing data indicates that the FCC did not survey those 
a subscriber-weighted averages of the 'competitive' and 'non-competitive' prices. The earlier figures are average prices within the 'non-competitive' portion of the survey sample. The prices do not include equipment (e.g., set-top box) rental fees.

Under the Cable Act, a cable operator may obtain a finding of 'effective competition' for a community that meets one of four tests: (1) fewer than 30 percent of households in the franchise area subscribe to the cable operator's service (low penetration test); (2) at least two MVPD providers each offer a comparable service to at least 50 percent of households and at least 15 percent of all households subscribe to service other than from the largest MVPD (50/15 test); (3) a municipality offers MVPD service to at least 50 percent of households (municipal test); or (4) a local exchange carrier (LEC) or its affiliate, or an MVPD using the facilities of such carrier or its affiliate, offers MVPD service by means other than direct broadcast satellite in an area that is also served by an unaffiliated cable operator (LEC test). ${ }^{20}$ The FCC is unable to take into account those areas of the country where no finding has been requested or made.

Figure II compares the average price in communities with no finding of 'effective competition' to the average prices in communities with findings of 'effective competition' based on different types of competition. ${ }^{21}$ The 'competition from DBS' category consists of communities satisfying the 50/15 test where one of the MVPDs is a direct broadcast satellite (DBS) operator. The 'competition from wireless cable operator' category consists of communities satisfying the LEC test, where the LEC is an MMDS operator. The 'competition from second cable operator' category consists of communities satisfying the 50/15 test where the two MVPDs are both cable operators, communities satisfying the municipal test (all these filings involve competition between two cable operators), and communities satisfying the LEC test where the LEC is a cable operator (as opposed to an MMDS

Footnote 19 Continued

metrics in that year. Data from 1995-2000 are averages for noncompetitive communities because composite subscriber-weighted averages of noncompetitive communities and 'effective competition' communities were not included in those survey reports. All other numbers are composite subscriber-weighted averages. For 1995, only a combined programming plus equipment price was reported, so the 1995 price was calculated by subtracting an estimate of equipment price. The CPI is from the BLS, Series ID CUUR0000SA0, All Items Less Food and Energy.

${ }^{20}$ See 47 C.F.R. $\$ 76.905(b)$. The term 'MVPD' refers to an entity such as, but not limited to, a cable operator that makes available for purchase multiple channels of video programming. See 47 C.F.R. $\$ 76.905(d)$. If a community is deemed subject to effective competition, the local franchising authority may no longer regulate basic service tier rates, unless it seeks and is granted recertification. See 47 U.S.C. $\$ 543(a)(2)$ and 47 U.S.C. $\S 916(\mathrm{a})$.

${ }^{21}$ Source: FCC Report on Cable Industry Prices (2006). 


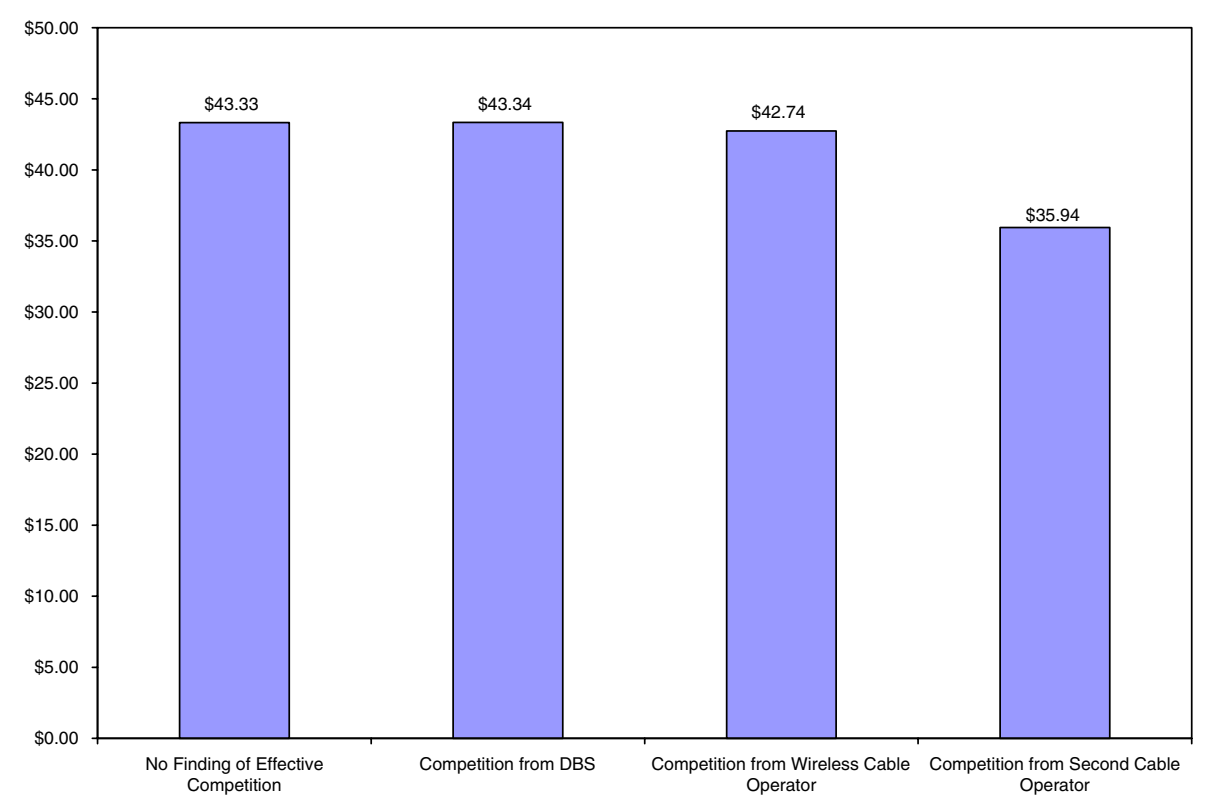

Figure II. Average Price for Cable Programming as of January 1, 2005 by Basis for Finding that Statutory Test for Effective Competition Has Been Met.

operator). The average price is $17.1 \%$ lower when the competition comes from a second cable operator, $1.4 \%$ percent lower when the competition comes from a wireless cable operator, and approximately the same (one cent higher) when the competition comes from a DBS operator.

It is perhaps interesting to consider changes in cable prices over time, particularly in comparison to prices for some other telecommunications services. As Figure III shows, ${ }^{22}$ since 1995 cable prices have increased far faster than inflation, while the prices of long distance and international wireline telephone calls and wireless telephone calls have decreased significantly.

${ }^{22}$ Sources: Cable Price (expanded basic) and CPI: See Table I. Long Distance Price Per Minute: Average Revenue per Minute for Interstate Calls, Industry Analysis and Technology Division, Wireline Competition Bureau, Telecommunications Industry Revenues (March 2005), available at www.fcc.gov/wcb/stats. International Price Per Minute: Average Revenue per Minute for International Calls 1/, Industry Analysis and Technology Division, Wireline Competition Bureau, Telecommunications Industry Revenues (March 2005), available at www.fcc.gov/wcb/stats. Wireless Price Per Minute: Average Revenue per Minute for Mobile Telephone, as reported in Table 8 of Wireless Telecommunications Bureau, Annual Report and Analysis of Competitive Market Conditions With Respect to Commercial Mobile Services, Tenth Report (September 2005). Underlying Source: CTIA, Background on CTIA's Semi-Annual Wireless Industry Survey< http://www.ctia.org/research_statistics/statistics/index.cfm/AID/10030 > (ARPU) and Dec 2004 CTIA Survey, at 219 (minutes of use). 


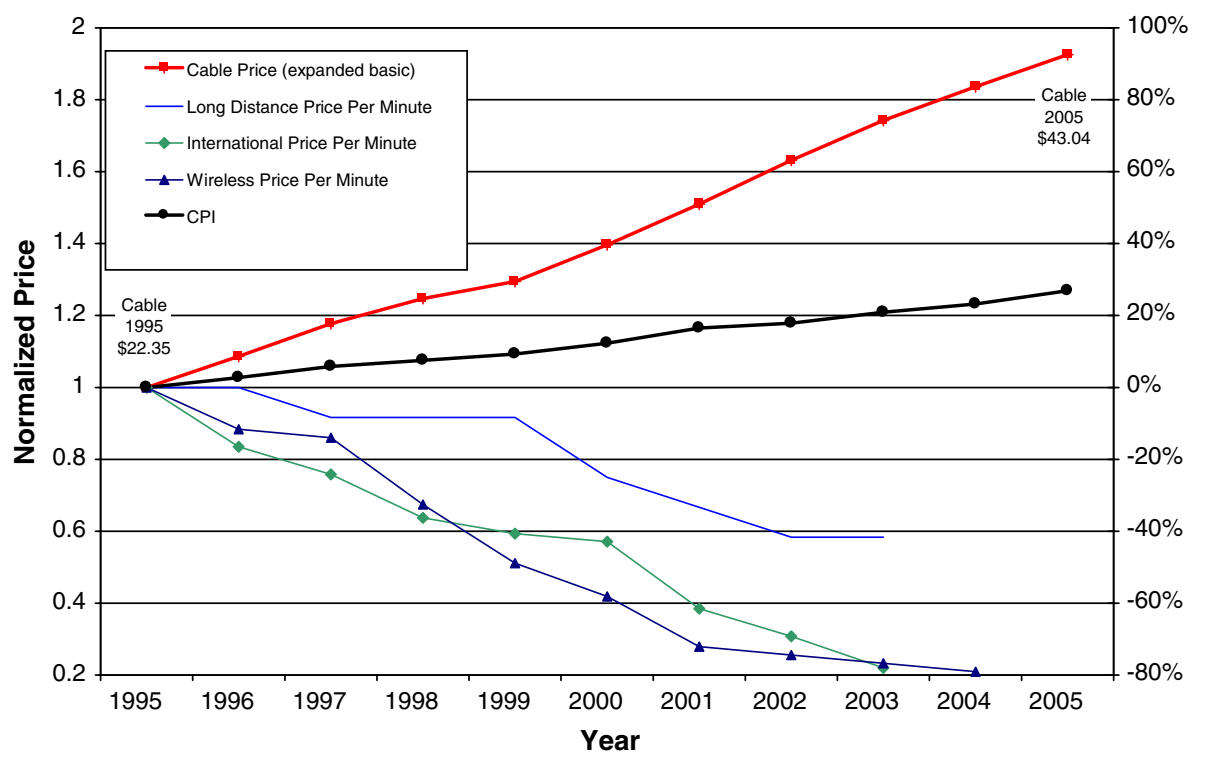

Figure III. Cable Rates and Prices of Other Communications Services.

Although the average number of cable channels has increased dramatically over time, the average number of cable channels watched by the typical household has not. ${ }^{23}$ As Figure IV shows, ${ }^{24}$ the price per cable channel watched has increased at a rate well above the rate of inflation.

One outgrowth of increasing cable prices has been a call for cable providers to offer channels on a more 'a la carte' basis, which is the subject of the next section.

${ }^{23}$ It is possible that with a larger set of channels from which to choose, even if consumers watch the same number of channels, they may be able to find a set of channels that more closely matches their preferences.

${ }^{24}$ Because of data limits, the data series have different beginning and ending dates. For the CPI and cable prices, the percentage change is from 1995 to 2005 . For long distance and international, the percentage change is from 1995 to 2003 . For wireless, the percentage change is from 1995 to 2004. Sources are as in Figure III, with additional sources as follows: Cable Price Per Channel Received: See Table I. Cable Price Per Channel Watched: Channels watched are calculated using the channels received from Table I and Nielsen Media Research, Television Audience 2004 at 14, which gives the percent tuned as a function of the number of channels received. Specifically, for $40-50$ received, 26\% are tuned; for $50-60$ received, $28 \%$ are tuned; for $60-70$ received, $23 \%$ are tuned; and for $70-80$ received, $21 \%$ are tuned. We assume the relationship between channels received and channels tuned is constant over time. 


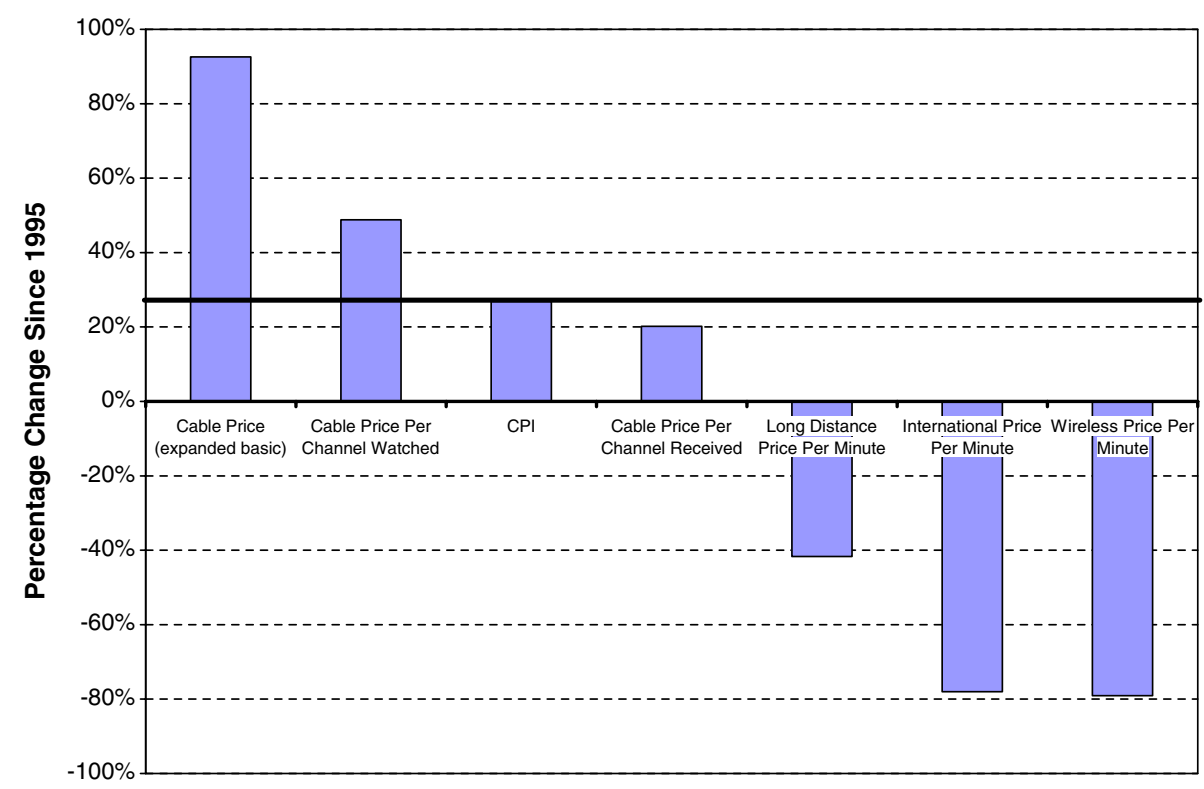

Figure IV. Changes in the Prices of Cable and Other Communications Services Since 1995.

\section{A LA CARTE PRICING}

FCC Chairman Kevin Martin has stated that he would like to see consumers of cable television have the choice to pay for only the programming that they want to come into their homes.

During the past year, the FCC has looked into the issue of providing consumers with more choice and has found that a la carte and other means for increasing consumer choice could benefit consumers. As discussed in the FCC's "Further Report On the Packaging and Sale of Video Programming Services To the Public," ${ }^{25}$ many consumers could gain more control while lowering their monthly bills.

An initial FCC report on a la carte made use of submissions from interested parties, including the cable industry. The industry submission presented several scenarios illustrating the impact of a la carte pricing on cable bills and concluded that monthly bills would rise. However, the Further Report finds (and a subsequent Congressional Research Service Report confirms $)^{26}$ that the earlier FCC report overstated the average price per cable channel under a la carte. The Further Report finds that, after

25 Available at http://www.fcc.gov/mb/.

${ }^{26}$ CRS Report for Congress, "The FCC's 'a la Carte' Reports," March 30, 2006, by Charles B. Goldfarb, available at http://www.opencrs.com/document/RL33338. 
correcting for mistakes made in the earlier FCC report, a la carte reduces consumers' bills in three out of the four scenarios considered.

The FCC's Further Report describes a number of ways that consumers could be given more choice. For example, a video provider could allow subscribers to block channels and get reimbursed (similar to Sports Illustrated's approach to its swimsuit issue), buy themed tiers (as in the U.K.), buy varying numbers of channels of their choosing for a corresponding price (as in Canada), or buy channels individually (as in Hong Kong).

In recent empirical work, Crawford (2005) examines the effect of bundling on the cable television market. ${ }^{27} \mathrm{He}$ finds that, consistent with the hypothesis that bundling is undertaken for the purpose of price discrimination, adding an additional popular cable network to the basic package increases the elasticity of demand for the package. Crawford then estimates the impact of bundling on consumer welfare, calculating that the bundling of an average top-15 cable network reduces consumer surplus by $5.5 \%$. Empirical work based on U.S. data is made difficult by the lack of a-la-carte offerings in the U.S. market. Thus, it is perhaps useful to examine cable offerings in other countries.

Themed tiers are available in the U.K., where subscribers of Britain's Sky TV can choose from a menu of themed packages, called "mixes" that include small numbers of channels. The "Variety mix" for example includes dramas, old classics, and comedies, while the "Style mix" offers food, fashion, travel and arts.

Subscriber-selected tiers (like ordering from a catering menu) are available in Canada, where Rogers Cable allows digital subscribers to add channels to the basic cable package $(\$ 25.99 \mathrm{CD})$ by purchasing pre-determined "theme packs" or by creating their own packages consisting of the channels of their choosing. For example, using current exchange rates, subscribers of Rogers Cable can purchase a single cable channel for about $\$ 2.25$; they can purchase five channels of their own choosing for about $\$ 9.00$; ten channels of their own choosing for about $\$ 13.55$; fifteen channels for $\$ 17.00$; twenty channels for $\$ 19.95$, etc.

Pure a la carte is available in Hong Kong. There, consumers can purchase cable channels from either Hong Kong Cable, owned by i-Cable, which offers a large bundle of channels in its "Basic Package" or from PCCW's Now TV, which offers its channels individually at monthly prices that start at less than $\$ 1.00$ per channel. In 2005, the monthly bills of consumers purchasing their video programming a la carte were approximately half of those for consumers subscribing to Hong Kong Cable. For half of

${ }^{27}$ In recent theoretical work, Rennhoff and Serfes (2005) present a model that predicts that in the television industry a regulation forcing downstream firms to unbundle would be beneficial for consumers. 
what a U.S. cable household might pay, a Hong Kong family who wants to watch sports, movies, news, and children's programming can obtain Hong Kong's 15 broadcast channels plus a selection of eleven additional channels including ESPN, CNN International, HBO, Disney Channel, Animal Planet, and Discovery.

The recent increase in competition has reversed the trend in Hong Kong's cable prices, which increased at rates far greater than inflation from 1995 to 2002, but then have actually fallen significantly since Now TV came on the scene. ${ }^{28}$ Hong Kong Cable attributes these decreases to the increased competitiveness of the market and has responded to consumer demand for more choice by offering mini-packages of its own.

\section{FRANCHISE REFORM}

The data and discussion above suggest that U.S. consumers might benefit from greater competition in the MVPD market. FCC Chairman Kevin Martin stated at the February 2006 Commission Meeting in Keller, Texas, that "We need to make sure that we are doing all we can to make sure the greater competition is promoted .... And we need to seek to eliminate any rules and regulation that are creating unreasonable barriers for people to come in and provide these services."

In the interest of promoting competition in the MVPD market, in November 2005 the FCC issued a notice of proposed rulemaking regarding Section 621(A)(1)'s directive that video franchising authorities not unreasonably refuse to award competitive franchises. ${ }^{29}$ As stated by Deborah Klein, Deputy Bureau Chief of the FCC's Media Bureau, at the November Commission Meeting,

"The notice of proposed rulemaking continues the Commission's ongoing efforts to provide consumers with the benefits of greater cable competition. This item initiates a rulemaking to determine whether the process by which cable franchises are granted creates barriers for would-be entrants, and if so, what the commission can and should do to ensure that this process doesn't unreasonably impede the development of cable competition." 30

${ }^{28}$ Based on i-Cable's Annual Reports, from 1995 to 2002, i-Cable's average revenue per subscriber increased 13\%. From 2002 to 2005, its average revenue per subscriber fell by $9 \%$.

${ }^{29}$ FCC-05-189, Implementation of Section 621(A)(1) of the Cable Communications Policy Act of 1984 as Amended by the Cable Television Consumer Protection and Competition Act of 1992, Released 11/18/2005.

30 Transcript from the FCC's November 2005 agenda meeting. 
Andrew Long of the Media Bureau elaborated, saying that

"the notice asks if local franchising authorities are unreasonably refusing to grant competitive franchises. In other words, does the franchising process in practice serve to create unreasonable barriers to entry for would-be competitive cable operators. Comments filed by a range of entities in our video competition proceeding suggest that the need to obtain franchises may unduly impede ability of potential competitors to enter the market in a timely fashion." ${ }^{1}$

By ensuring that local authorities are not unreasonably refusing to award competitive franchises, ${ }^{32}$ the FCC can fulfill Congress's directive and promote competition in the MVPD market. ${ }^{33}$

\section{Net Neutrality}

In Section 230(b) of the Communications Act of 1934, as amended, Congress describes its national Internet policy. Specifically, Congress states that it is the policy of the United States "to preserve the vibrant and competitive free market that presently exists for the Internet" 34 and "to promote the continued development of the Internet." ${ }^{35}$ In Section 706(a) of the Act, Congress charges the FCC with "encourag[ing] the deployment on a reasonable and timely basis of advanced telecommunications capability" - broadband - "to all Americans." 36

Consistent with these Congressional directives, in September 2005 the FCC issued a Policy Statement listing a set of principles designed to

31 Transcript from the FCC's November 2005 agenda meeting.

32 Section 621 of the Communications Act of 1934, as amended (codified at 47 USC section 541(a)(1)) states that “... a franchising authority may not grant an exclusive franchise and may not unreasonably refuse to award an additional competitive franchise. Any applicant whose application for a second franchise has been denied by a final decision of the franchising authority may appeal such final decision pursuant to the provisions of section 635 for failure to comply with this subsection." Although some local authorities might prefer to authorize only one cable provider, by doing so they may prevent potential entrants from being able to achieve economies of scope and so impose a negative externality on other local authorities that prefer competition.

33 As stated in House Committee on Energy and Commerce, H.R. Conf. Rep. No. 102-862, 102d Cong., 2d Sess. at p.77, "The conferees believe that exclusive franchises are directly contrary to federal policy and to the purposes of S.12, which is intended to promote the development of competition. Exclusive franchises artificially protect the cable operator from competition."

3447 U.S.C. $\$ 230(b)(2)$.

3547 U.S.C. $\$ 230(\mathrm{~b})(1)$.

3647 U.S.C. $\$ 157$ nt. (incorporating section 706 of the Telecommunications Act of 1996, Pub. Law No. 104-104, 110 Stat.56 (1996)). 
ensure that broadband networks are widely deployed, open, affordable, and accessible to all consumers. ${ }^{37}$ The principles are as follows (Policy Statement at 3):

- To encourage broadband deployment and preserve and promote the open and interconnected nature of the public Internet, consumers are entitled to access the lawful Internet content of their choice.

- To encourage broadband deployment and preserve and promote the open and interconnected nature of the public Internet, consumers are entitled to run applications and use services of their choice, subject to the needs of law enforcement.

- To encourage broadband deployment and preserve and promote the open and interconnected nature of the public Internet, consumers are entitled to connect their choice of legal devices that do not harm the network. ${ }^{38}$

- To encourage broadband deployment and preserve and promote the open and interconnected nature of the public Internet, consumers are entitled to competition among network providers, application and service providers, and content providers. ${ }^{39}$

As stated in the Policy Statement, ${ }^{40}$ the principles are subject to reasonable network management.

The topic of network neutrality continues to be debated in many places and would benefit from additional research, ${ }^{41}$ possibly including theoretical, empirical, and experimental work. As stated in Weitzner (2006, p. 1):

"At the heart of the debate is the question of whether Internet Service Providers ought to be subject to a non-discrimination (aka neutrality) requirement. The pro neutrality camp has argued that neutrality must be legally mandated lest we lose the benefits that the Internet has enabled. Those opposed to neutrality requirements generally view the Internet as a good thing, too; they argue, however, that market forces will assure continued access to the Internet on reasonably neutral terms, and that legislating this requirement will stifle investment in new broadband services."

37 FCC Policy Statement in the Matter of the Appropriate Framework for Broadband Access to the Internet over Wireline Facilities, FCC 05-151, September 23, 2005, available at http://hraunfoss.fcc.gov/edocs_public/attachmatch/FCC-05-151A1.pdf.

38 See Hush-A-Phone Corp. v. United States, 238 F.2d 266, 269 (D.C. Cir. 1956); Use of the Carterfone Device in Message Toll Telephone Service, 13 FCC 2d 420 (1968).

39 See Preamble, Telecommunications Act of 1996, P.L. 104-104, 100 Stat. 56 (1996) (enacting 1996 Act "to promote competition and reduce regulation in order to secure lower prices and higher quality services for American telecommunications consumers and encourage the rapid deployment of new telecommunications technologies").

40 See footnote 37.

41 For background and discusion, see http://en.wikipedia.org/wiki/Network_neutrality. 


\section{Conclusion}

In conclusion, this article reviews several issues that FCC economists addressed over the past year and explains some of the analyses used in examining those issues. Section 2 describes how a desire to let market forces work affected the design of Auction 65, and how concerns about collusion and strategic bidding affected the design of Auction 66. Section 3 describes issues of prices and competition in the MVPD market. Section 4 deals with the topic of net neutrality.

\section{References}

Brusco, S., and G. Lopomo (2002) 'Collusion Via Signaling in Simultaneous Ascending Bid Auctions with Multiple Objects and Complementarities', The Review of Economic Studies, 69(2), 407-436.

Cramton, P. (1997) 'The FCC Spectrum Auctions: An Early Assessment', Journal of Economics and Management Strategy, 6(3), 431-495.

Cramton, P., and J. A. Schwartz (1999) 'Collusive Bidding in the FCC Spectrum Auctions', Working Paper, University of Maryland.

Cramton, P., and J. A. Schwartz (2000) 'Collusive Bidding: Lessons from the FCC Spectrum Auctions', Journal of Regulatory Economics, 17, 229-252.

Cramton, P., and J. A. Schwartz (2002) 'Collusive Bidding in the FCC Spectrum Auctions', Contributions to Economic Analysis and Policy (Article 11) 1(1), 1-18.

Crawford, G. S. (2005) The 'Discriminatory Incentives to Bundle in the Cable Television Industry', University of Arizona Working Paper.

Grimm, V., F. Riedel, and E. Wolfstetter (2001) 'Low Price Equilibrium in Multi-Unit Auctions: The GSM Spectrum Auction in Germany', Working Paper, Humboldt Universität zu Berlin.

Jehiel, P., and B. Moldovanu (2001) 'The UMTS/IMT-2000 License Auctions', Working Paper, University College London and University of Mannheim.

Klemperer, P. (2002) 'What Really Matters in Auction Design', Journal of Economic Perspectives, 16(1), 169-189.

Kwasnica, A. M., and K. Sherstyuk (2001) 'Collusion via Signaling in Multiple Object Auctions with Complementarities: An Experimental Test', Working Paper, Penn State University.

Kwerel, E. R., and G. L. Rosston (2000) 'An Insiders' View of FCC Spectrum Auctions', Journal of Regulatory Economics, 17(3), 253-289.

Marshall, R. C., and L. M. Marx (2006) 'Bidder Collusion', in press in Journal of Economic Theory, http://www.science direct.com/science/journal/0022053.

McAfee, R. P., and J. McMillan (1987) 'Auctions and Bidding', Journal of Economic Literature, 25 699-738.

McAfee, R. P., and J. McMillan (1996) 'Analyzing the Airwaves Auctions', Journal of Economic Perspectives, 10(1), 159-175.

McMillan, J. (1994) 'Selling Spectrum Rights', Journal of Economic Perspectives, 8(3), $145-162$.

Milgrom, P. (2004) 'Putting Auction Theory to Work'. Cambridge, UK: Cambridge University Press.

Rennhoff, A. D., and K. Serfes (2005) 'The Role of Upstream- Downstream Competition on Bundling Decisions: Should Regulators Force Firms to Unbundle?', Working Paper, Drexel University. 
Stuewe, H. (1999) 'Auktion von Telefonfrequenzen: Spannung bis zur letzten Minute', Frankfurter Allgemeine Zeitung, October 29.

Weitzner, D. J. (2006) 'The Neutral Internet: An Information Architechture for Open Societies', Working Paper, MIT. 